Check for updates

Cite this: RSC Adv., 2017, 7, 19828

Received 24th January 2017

Accepted 30th March 2017

DOI: 10.1039/c7ra01062a

rsc.li/rsc-advances

\section{Preparation of cellulose nanofibers coated with poly(vinyl alcohol) crystals and their application in composite films $\uparrow$}

\begin{abstract}
Tetsuya Uchida, D* Fumiaki Iwaguro, Risa Yanai and Haruka Dodo
Poly(vinyl alcohol) (PVA) was crystallized from a dilute solution in the presence of cellulose nanofibers (CeNFs). The CeNFs acted as nucleating agents for PVA crystallization, and PVA crystals were grown on the CeNFs' surface. As a result, CeNFs coated with PVA crystals (CeNF/PVA nanocomposite fiber $\left(\mathrm{NCF}_{(\mathrm{CeNF} / \mathrm{PVA})}\right)$ ) were successfully obtained. The $\mathrm{NCF}_{(\mathrm{CeNF} / \mathrm{PVA})}$ showed good dispersibility in water even after drying. Composite films were prepared using the aforementioned $\mathrm{NCF}_{(\mathrm{CeNF} / \mathrm{PVA})}$ and their mechanical properties were measured. Despite the low content of NCF(CeNF/PVA=1/5) $(0.1 \mathrm{wt} \%$, corresponding to $1.7 \times 10^{-2}$ wt\% CeNF), the mechanical properties of the composite films improved in comparison to those of the control samples. This reinforcement effect of the $N C F_{(C e N F / P V A=1 / 5)}$ was greater than that of pure CeNFs. Surface modification of the NCF was also discussed, and the surface hydrophilicity of the NCF could be controlled depending on the choice of coating crystal.
\end{abstract}

\section{Introduction}

Cellulose nanofibers (CeNFs) exhibit excellent properties such as high Young's modulus, high tensile strength, ${ }^{1-6}$ low thermal expansion coefficient, ${ }^{7}$ and high aspect ratio. ${ }^{8}$ Therefore, these materials are considered highly promising for synthesizing high-performance nanocomposites. In order to enhance the properties of the nanocomposite as desired, CeNFs should be homogeneously dispersed in a matrix and properly bound to that matrix. However, individual CeNFs cannot be dispersed after drying because of their high cohesiveness. As a result, achieving good dispersion of CeNFs in a matrix is problematic, and obtaining the prospective additive effects from the CeNFs is difficult. Various studies have sought to overcome these difficulties through the substitution of the hydroxyl group on the surface of the $\mathrm{CeNFs}^{9-16}$ and through the use of effective dispersants. ${ }^{17-19}$ Furthermore, these studies have aimed to modify the CeNFs' surface properties such as its hydrophilicity. Although the CeNFs would be ideally expected to reinforce the nanocomposites at a much lower concentration of CeNF than that of the fillers typically used in conventional composites ${ }^{20}$ its concentration is relatively high which is higher than several percent. This is because such CeNF composites (CeNF conc. several \%) sacrifice the dispersibility of the CeNFs in the composite to improve the processability of the nanocomposite.

Graduate School of Natural Science and Technology, Okayama University, 3-1-1 Tsushima-naka, Kitaku, Okayama 700-8530, Japan. E-mail: tuchida@cc.okayama-u. ac.jp

$\dagger$ Electronic supplementary information (ESI) available. See DOI: 10.1039/c7ra01062a
In this study, preparation of CeNFs coated with crystals of poly(vinyl alcohol) (PVA) (CeNF/PVA nanocomposite fibers $\left.\left(\mathrm{NCF}_{(\mathrm{CeNF} / \mathrm{PVA})}\right)\right)$ was examined to change the surface properties of the CeNFs in a way that would inhibit the aggregation of CeNFs, leading to the improvement of the dispersibility of CeNFs in composites. Furthermore, composite films were prepared using $\mathrm{NCF}_{(\mathrm{CeNF} / \mathrm{PVA})} \mathrm{S}$ at extremely low concentrations of CeNFs $(\leq 0.1$ $\mathrm{wt} \%$ ), and their mechanical properties were examined. In addition, in order to modify the surface hydrophilicity of the CeNFs, they were coated with other polymer crystals such as poly(vinyl alcohol-co-ethylene) (EVOH) $\left(\mathrm{NCF}_{(\mathrm{CeNF} / \mathrm{EVOH})}\right)$ and formalized PVA crystal $\left(\mathrm{NCF}_{(\mathrm{CeNF} / \text { formalized } \mathrm{PVA})}\right)$, and their surface hydrophilicity was discussed.

\section{Experimental}

\subsection{Materials}

The CeNFs were purchased from Daisel Fine Chem Ltd. (Trade name Celish KY100G). The PVA was purchased from SigmaAldrich, and its molecular weight and degree of saponification were $89000-98000 \mathrm{~g} \mathrm{~mol}^{-1}$ and $\geq 99 \%$, respectively. The EVOH was purchased from Sigma-Aldrich, and its ethylene content was $27 \mathrm{~mol} \%$. 1,3-Butanediol was purchased from Nacalai Tesque Inc. and used as received. Formaldehyde solution (37\%) and sulfuric acid (98\%) were purchased from Kishida Chemical Co., Ltd.

\subsection{Coating CeNFs with PVA crystals}

CeNFs were dispersed in water via sonication. After standing and settling for one day, the supernatant was collected as 
a water dispersion of the CeNFs. After adding 1,3-butanediol to the water dispersions, solvent substitution was performed via the distillation of water under vacuum. The concentration of the CeNFs in the 1,3-butanediol dispersion was adjusted to $2 \times$ $10^{-3} \mathrm{wt} \%$. The $\mathrm{NCF}_{(\mathrm{CeNF} / \mathrm{PVA})}$ was obtained by dissolving the PVA in the 1,3-butanediol dispersions of the CeNFs at $182^{\circ} \mathrm{C}$ and the following cooling to $25{ }^{\circ} \mathrm{C}$ with a cooling rate of $5{ }^{\circ} \mathrm{C}$ hour ${ }^{-1}$ under stirring. ${ }^{21}$ During this cooling process, crystallization temperature of the PVA crystals was determined by the clouding point of the crystallization solution.

\subsection{Coating CeNFs with EVOH crystals}

$\mathrm{NCF}_{(\mathrm{CeNF} / \mathrm{EVOH})}$ was prepared by dissolving EVOH in the 1,3butanediol dispersions of the CeNFs at $182{ }^{\circ} \mathrm{C}$ and the following cooling to $25{ }^{\circ} \mathrm{C}$ with a cooling rate of $5{ }^{\circ} \mathrm{C}$ hour ${ }^{-1}$ under stirring. The crystallization temperature of the EVOH crystal was determined by the clouding point of the crystallization solution.

\subsection{Formalization of PVA crystals on CeNF surface}

The surface treatment of the PVA crystals of the $\mathrm{NCF}_{(\mathrm{CeNF} / \mathrm{PVA})}$ was modified by the previous procedure. ${ }^{22}$ Water dispersions $(60.0 \mathrm{~g})$ of $1 \mathrm{wt} \% \mathrm{NCF}_{(\mathrm{CeNF} / \mathrm{PVA})}$, sulfuric acid $(0.5 \mathrm{~g})$, and formaldehyde $(1.0 \mathrm{~g})$ were placed in an eggplant-shaped flask equipped with a gas bag filled with nitrogen. The mixture was stirred at $45{ }^{\circ} \mathrm{C}$ for $36 \mathrm{~h}$ and the precipitates were collected by vacuum filtration before being washed with water.

\subsection{Preparation of $\mathrm{NCF}_{(\mathrm{CeNF} / \mathrm{PVA})} / \mathrm{PVA}$ composite film}

PVA $(0.25 \mathrm{~g})$ and water $(10.0 \mathrm{~g})$ were placed in an eggplantshaped flask equipped with a condenser. The mixture was stirred at $95{ }^{\circ} \mathrm{C}$ for $1 \mathrm{~h}$. The PVA/water solution was then allowed to cool to $25{ }^{\circ} \mathrm{C}$. The PVA/water solution (10.25 g) and the $\mathrm{NCF}_{(\mathrm{CeNF} / \mathrm{PVA})}$ water dispersions of $2.5 \times 10^{-3} \mathrm{wt} \%(10.0 \mathrm{~g})$ were mixed and placed into a Petri dish. The $\mathrm{NCF}_{(\mathrm{CeNF} / \mathrm{PVA})} / \mathrm{PVA}$ composite film was obtained after drying at $70{ }^{\circ} \mathrm{C}$.

\subsection{Preparation of NCF sheet}

The NCFs dispersed in water were filtered using a polycarbonate membrane filter (Millipore, pore size $0.2 \mu \mathrm{m}$ ) under vacuum. The obtained NCF sediment was pressed under vacuum at $65^{\circ} \mathrm{C}$ to prepare the NCF sheet. Its porosity was calculated from both the apparent density of the obtained sheet and the theoretical density of the NCFs.

\subsection{Measurements}

The morphology of the sample was observed on a JEOL JSM6320F scanning electron microscope (SEM) and a JEOL JEM2000EX transmission electron microscope (TEM) at an acceleration voltage of $200 \mathrm{kV}$. The light transmittance of the films was measured by a Hitachi U-1900 ultraviolet-visible light spectrophotometer. FTIR spectra of the samples were obtained with a Shimazu IR Affinity-1S. The mechanical properties of the films were measured by an Imada SV-201NA universal testing machine. The initial grip separation of the machine was set at $10 \mathrm{~mm}$ and the specimens were loaded at a constant cross-head speed of $4 \mathrm{~mm} \mathrm{~min}^{-1}$. All the film samples (thickness $\mathrm{ca} .20 \mu \mathrm{m}$ ) were cut into rectangular strips with the size of $5 \mathrm{~mm} \times 20 \mathrm{~mm}$. The contact angles of the water droplets on the sheetswere measured by a Kyowa Interface Science CA-D contact angle meter at $25{ }^{\circ} \mathrm{C}$. The apparent densities of the obtained sheets were calculated from the weight and volume of the sheets.

\section{Results and discussion}

\subsection{Preparation of $\mathrm{NCF}_{(\mathrm{CeNF} / \mathrm{PVA})}$}

The CeNF dispersion in water was freeze-dried onto a mica surface and SEM observations were performed. Isolated CeNFs were observed as shown in Fig. 1(a). The morphology of the CeNFs dispersed in the 1,3-butanediol was observed in a similar way. Aggregated CeNFs were not observed and the CeNFs were individually isolated as shown in Fig. 1(b). The diameter of the CeNFs dispersed in the water was the same as those in 1,3butanediol, which was approximately $50 \mathrm{~nm}$. As a result, the CeNF dispersion in 1,3-butanediol was used for the crystallization of the PVA.

The crystallization temperature of the PVA in the presence of the CeNFs was examined by observing the clouding point.

The clouding point became higher by the presence of the CeNFs, as shown in Fig. 2(a). This reveals that the PVA crystallized at higher temperature in the presence of the CeNFs, indicating that the CeNFs worked as nucleating agents for PVA crystallization as well as the behavior of rigid polymer poly $(p$ phenylene benzobisthiazole)(PBZT) in the presence of carbon nanotubes. ${ }^{23}$

SEM and TEM observations were performed to clarify the influence of the CeNFs on the morphology of the PVA crystals. The PVA crystals prepared from the PVA dilute solution without the CeNFs were spherulitic aggregates of the lamellar crystals of which the diameter was ca. $10 \mu \mathrm{m}$, as shown in Fig. 3(a) and (b). The electron diffraction of the PVA spherulites showed 101 and 200 reflection peaks of the PVA crystals, as shown in the inset of Fig. 3(b). ${ }^{21,24}$ The crystallization of the PVA in the presence of the CeNFs also resulted in the formation of PVA spherulites, but it was noteworthy that several PVA spherulites were connected by narrow fibers, as shown in Fig. 3(c)-(f). The diameter of the narrow fibrous part is approximately $50 \mathrm{~nm}$, which was the same as that of the pristine CeNF. In addition, the PVA part in NCFs showed the crystalline reflection peaks of the PVA crystals, as shown in Fig. S1. $\dagger$ In the FTIR spectroscopy, the difference was not observed between NCF and PVA film, as shown in

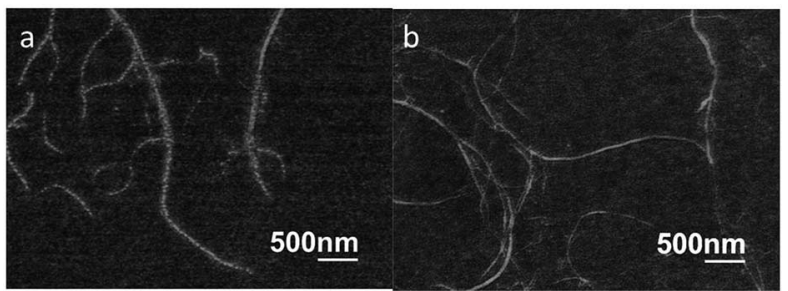

Fig. 1 Scanning electron micrographs of CeNFs dried from (a) water and (b) 1,3-butanediol. 

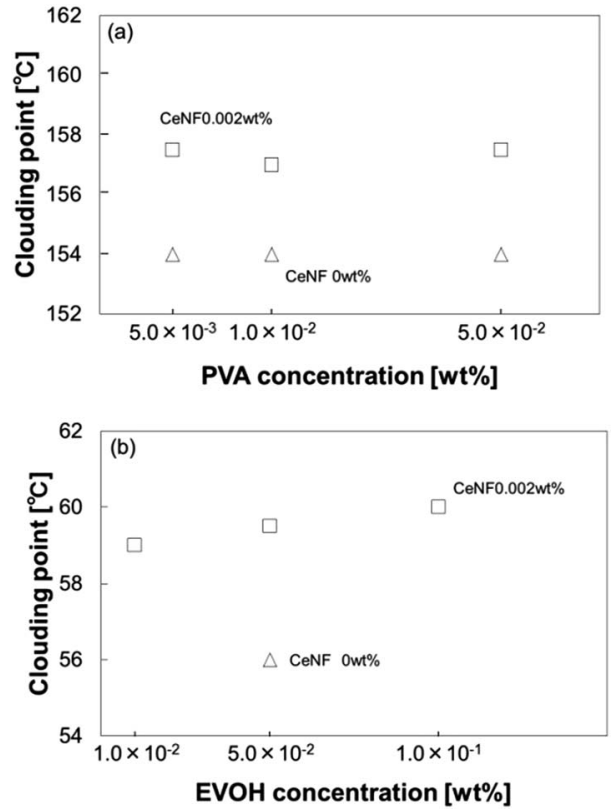

Fig. 2 Plots of clouding point of (a) PVA and (b) EVOH as a function of concentration.

Fig. S2. $\dagger$ Based on these observations, the schematic illustration of $\mathrm{NCF}_{(\mathrm{CeNF} / \mathrm{PVA}=1 / 50)}$ (Fig. 3(f)) was shown in Fig. 3(g). As shown in Fig. 3(g), PVA spherulites were grown up from the CeNF and PVA spherulites were connected with the CeNF. The diameter of PVA spherulite of $\mathrm{NCF}_{(\mathrm{CeNF} / \mathrm{PVA}=1 / 5)}, \quad \mathrm{NCF}_{(\mathrm{CeNF} / \mathrm{PVA}=1 / 10)}$, $\mathrm{NCF}_{(\mathrm{CeNF} / \mathrm{PVA}=1 / 25)}$ and $\mathrm{NCF}_{(\mathrm{CeNF} / \mathrm{PVA}=1 / 50)}$ were $0.5 \mu \mathrm{m}, 1.2 \mu \mathrm{m}$, $1.6 \mu \mathrm{m}$ and $2.5 \mu \mathrm{m}$, respectively. These results imply that the

\section{CeNF}
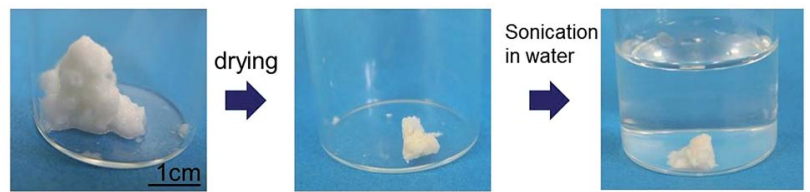

$\mathrm{NCF}_{(\mathrm{CeNF} / \mathrm{PVA}=1 / 5)}$
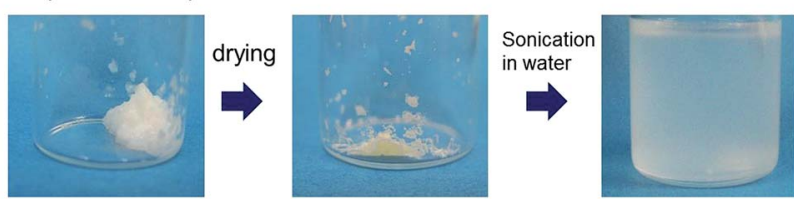

Fig. 4 Dispersibility of $C e N F$ and $N C_{(C e N F / P V A=1 / 5)}$ in water.

diameter of the PVA spherulite could be controlled via the concentration of the PVA solution. In addition, detail observation reveals that each spherulite was comprised of thin lamellar crystals with sharp edges. The morphology increased the surface area of the NCF, which might bring the stronger reinforcement effect for the composite.

The dried $\mathrm{NCF}_{(\mathrm{CeNF} / \mathrm{PVA}=1 / 5)}$ was easily dispersed in water by sonication and a well-dispersed solution was obtained as shown in Fig. 4. The dried $\mathrm{NCF}_{(\mathrm{CeNF} / \mathrm{PVA}=1 / 10),} \mathrm{NCF}_{(\mathrm{CeNF} / \mathrm{PVA}=1 / 25)}$ and $\mathrm{NCF}_{(\mathrm{CeNF} / \mathrm{PVA}=1 / 50)}$ were also easily dispersed in water. Conversely, dried pristine CeNFs could not be dispersed by sonication. This result shows that the PVA crystals grown on the surface of CeNFs improve the dispersibility of CeNFs. In addition, it was found that the diameter of PVA of NCF did not have an influence on the dispersibility.
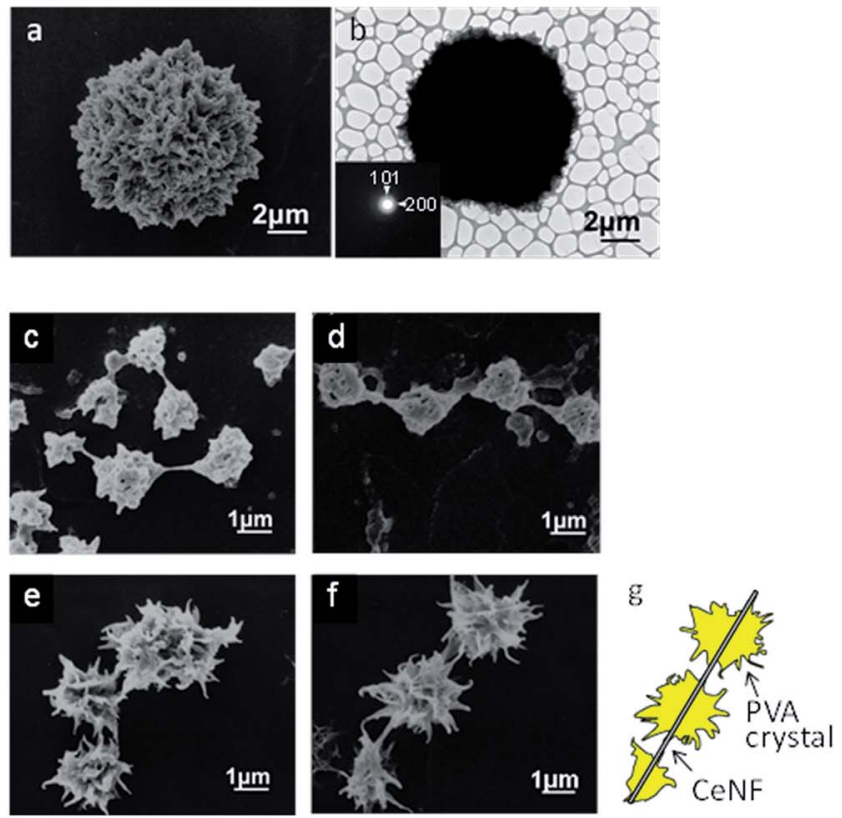
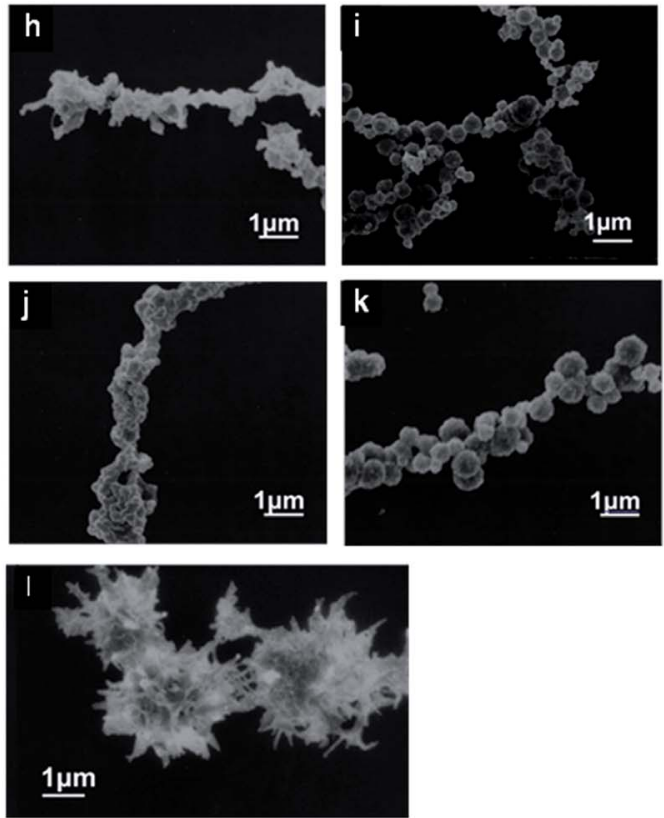

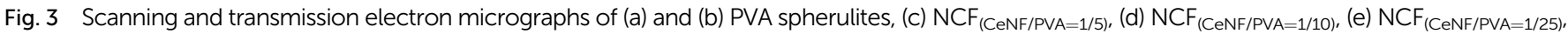

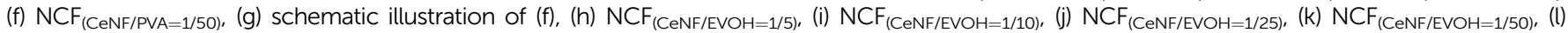

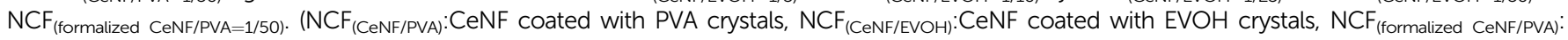
CeNF coated with formalized PVA crystals). 


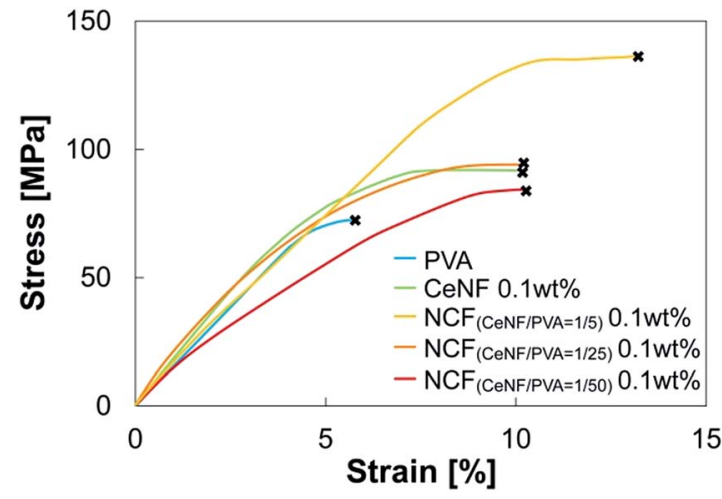

Fig. 5 Stress-strain curves of PVA film, pristine CeNF/PVA composite film, and $\mathrm{NCF}_{(\mathrm{CeNF} / \mathrm{PVA})} / \mathrm{PVA}$ composite films.

\subsection{Preparation of PVA composite film using $\mathbf{N C F}_{(\mathrm{CeNF} / \mathrm{PVA})}$ and its mechanical properties}

The resultant $\mathrm{NCF}_{(\mathrm{CeNF} / \mathrm{PVA})} / \mathrm{PVA}$ composite film, of which the thickness was ca. $20 \mu \mathrm{m}$, was transparent (optical transmittance $\geqq 90 \%$ ) and colorless, just like both the pristine CeNF/PVA composite film and PVA film. In addition, the difference was not observed between $\mathrm{NCF}_{(\mathrm{CeNF} / \mathrm{PVA})} / \mathrm{PVA}$ composite film and PVA film in the FTIR spectroscopy, as shown in Fig. S2. $\dagger$ This result showed that the addition of the NCF to the PVA matrix did not cause the structural and chemical change of the PVA matrix. ${ }^{25}$ The stress-strain curve of the PVA, pristine CeNF/PVA composite, and $\mathrm{NCF}_{(\mathrm{CeNF} / \mathrm{PVA})} / \mathrm{PVA}$ composite films are shown in Fig. 5, and their mechanical properties are listed in Table 1. The tensile strength and the elongation at break of the $\mathrm{NCF}_{(\mathrm{CeNF} / \mathrm{PVA}=1 / 5)} / \mathrm{PVA}$ composite film were $121.7 \mathrm{MPa}$ and $11.5 \%$, respectively, and they were the highest values. Despite the extremely low NCF content $(0.1 \mathrm{wt} \%$, corresponding to $1.7 \times$ $10^{-2} \mathrm{wt} \% \mathrm{CeNF}$ ), the mechanical properties of the composite are significantly improved by the $\mathrm{NCF}_{(\mathrm{CeNF} / \mathrm{PVA}=1 / 5)}$. Such dramatic change of the mechanical properties of the composite film had not been observed in the case of $0.1 \mathrm{wt} \%$ pristine CeNF. These results show that the reinforcement effect of the $\mathrm{NCF}_{(\mathrm{CeNF} / \mathrm{PVA}=1 / 5)}$ was higher than that of the pristine CeNF. On the other hand, such significant reinforcement effect was not observed in other NCF. Even though the CeNF content was increased in $1.7 \times 10^{-2} \mathrm{wt} \%$, the results were almost the same. These results indicate that the diameter of the PVA spherulite of the NCF have an effect on the mechanical properties of $\mathrm{NCF}_{(\mathrm{CeNF} / \mathrm{PVA})} / \mathrm{PVA}$ composite films. The observation of the fractured surface of the $\mathrm{NCF}_{(\mathrm{CeNF} / \mathrm{PVA})} / \mathrm{PVA}$ composite film

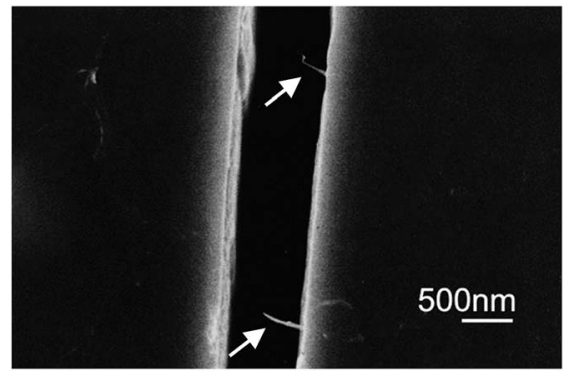

Fig. 6 Scanning electron micrograph of fractured surface of PVA/ $\mathrm{NCF}_{(\mathrm{CeNF} / \mathrm{PVA}=1 / 5)}$ composite film (NCF $0.1 \mathrm{wt} \%$, corresponding to 0.017 wt\% CeNF). Arrows show isolated CeNF. The diameter of the CeNF is approximately $50 \mathrm{~nm}$.

showed that the isolated CeNFs stood upright on the surface as shown in Fig. 6 (see arrows). In this image, the diameter of the CeNF is approximately $50 \mathrm{~nm}$. In addition, PVA spherulites cannot be observed on the CeNFs. This result reveals that the NCFs were dispersed in the composite film without aggregation, and the PVA spherulites were pulled out from the CeNF surface of the $\mathrm{NCF}_{(\mathrm{CeNF} / \mathrm{PVA})}$ on the fracture surface. As mentioned before, the PVA crystal coating of the CeNFs increased the surface area and roughness of the $\mathrm{NCF}_{(\mathrm{CeNF} / \mathrm{PVA})}$. In the case of the $\mathrm{NCF}_{(\mathrm{CeNF} / \mathrm{PVA})} / \mathrm{PVA}$ composite, this $\mathrm{NCF}_{(\mathrm{CeNF} / \mathrm{PVA})}$ morphology may have caused an anchor effect in the mechanical properties of the composite. In addition, the size and structure of the $\mathrm{NCF}_{(\mathrm{CeNF} / \mathrm{PVA}=1 / 5)}$ was suitable for the reinforce effect of the composite film. Therefore, the $\mathrm{NCF}_{(\mathrm{CeNF} / \mathrm{PVA}=1 / 5)}$ dramatically improved the mechanical properties of the PVA films.

\subsection{Surface modification of CeNFs using EVOH and formalized PVA crystals}

EVOH and formalized PVA are hydrophobic in comparison to pristine PVA. Therefore, CeNFs coated with EVOH crystals and formalized PVA crystals were prepared as to change the surface properties of the NCF. First, the clouding point of EVOH was measured as well as PVA and they were plotted as a function of the concentration in Fig. 2(b). The clouding point of the EVOH increased in the presence of the CeNFs, suggested that the CeNFs worked as nucleating agents for the crystallization of the EVOH as well as for the PVA. The crystallization of the EVOH in the presence of the CeNFs resulted in the formation of $\mathrm{EVOH}$ spherulites connected by narrow fibers, as shown in Fig. 2(h)(k). The surface of the EVOH spherulites was smoother than

Table 1 Mechanical properties of NCF/PVA films

\begin{tabular}{|c|c|c|c|}
\hline Film & Modulus [GPa] & $\begin{array}{l}\text { Tensile strength } \\
\text { at break [MPa] }\end{array}$ & $\begin{array}{l}\text { Elongation at } \\
\text { break [\%] }\end{array}$ \\
\hline PVA & $1.83 \pm 0.34$ & $71.1 \pm 31.3$ & $7.4 \pm 2.1$ \\
\hline PVA + pristine CeNF $0.1 \mathrm{wt} \%$ & $1.90 \pm 0.27$ & $82.9 \pm 20.3$ & $10.5 \pm 2.5$ \\
\hline $\mathrm{PVA}+\mathrm{NCF}_{(\mathrm{CeNF} / \mathrm{PVA}=1 / 5)} 0.1 \mathrm{wt} \%$ & $1.83 \pm 0.44$ & $121.7 \pm 49.2$ & $11.5 \pm 3.5$ \\
\hline $\mathrm{PVA}+\mathrm{NCF}_{(\mathrm{CeNF} / \mathrm{PVA}=1 / 25)} 0.1 \mathrm{wt} \%$ & $2.19 \pm 0.17$ & $83.9 \pm 9.5$ & $11.7 \pm 2.7$ \\
\hline $\mathrm{PVA}+\mathrm{NCF}_{(\mathrm{CeNF} / \mathrm{PVA}=1 / 50)} 0.1 \mathrm{wt} \%$ & $1.39 \pm 0.15$ & $83.4 \pm 7.3$ & $11.1 \pm 0.7$ \\
\hline
\end{tabular}


Table 2 Porosity and contact angle of water droplet of NCF sheets

\begin{tabular}{lll}
\hline Sheet & Porosity [\%] & $\begin{array}{l}\text { Contact angle of } \\
\text { water droplet }\left[{ }^{\circ}\right]\end{array}$ \\
\hline $\mathrm{NCF}_{(\mathrm{CeNF} / \mathrm{PVA}=1 / 5)}$ & 24 & 10 \\
$\mathrm{NCF}_{(\mathrm{CeNF} / \mathrm{EVOH}=1 / 5)}$ & 22 & 24 \\
$\mathrm{NCF}_{(\text {formalized CeNF/PVA=1/5) }}$ & 22 & 34
\end{tabular}

that of the PVA spherulites. This is because the copolymer component of EVOH reduced the crystallinity and crystal habit of EVOH crystals. As a result, lamellar structure could not be observed on the $\mathrm{NCF}_{(\mathrm{CeNF} / \mathrm{EVOH})}$ surface. For the same reason, clouding point of the EVOH was lower than that of PVA as shown in Fig. 2. The diameter of $\mathrm{EVOH}$ spherulite of $\mathrm{NCF}_{(\mathrm{CeNF} / \mathrm{EVOH}=1 / 5)}, \mathrm{NCF}_{(\mathrm{CeNF} / \mathrm{EVOH}=1 / 10)}, \mathrm{NCF}_{(\mathrm{CeNF} / \mathrm{EVOH}=1 / 25)}$ and $\mathrm{NCF}_{(\mathrm{CeNF} / \mathrm{EVOH}=1 / 50)}$ were $0.5 \mu \mathrm{m}, 1.0 \mu \mathrm{m}, 1.5 \mu \mathrm{m}$ and $1.8 \mu \mathrm{m}$ respectively. These results show that the diameter of the $\mathrm{EVOH}$ spherulite of the $\mathrm{NCF}_{(\mathrm{CeNF} / \mathrm{EVOH})}$ could be controlled via the concentration of the EVOH solution as well as $\mathrm{NCF}_{(\mathrm{CeNF} / \mathrm{PVA})}$.

On the other hand, the morphology of the pristine $\mathrm{NCF}_{(\mathrm{CeNF} / \mathrm{PVA})}$ and the $\mathrm{NCF}_{(\mathrm{CeNF} / \text { formalized PVA) }}$ were almost the same, as shown in Fig. 2(f) and (l), showing that the formalization process did not change the morphology of the PVA crystals.

In order to examine the surface properties of the NCFs, NCF sheets were prepared by using $\mathrm{NCF}_{(\mathrm{CeNF} / \mathrm{PVA})}, \mathrm{NCF}_{(\mathrm{CeNF} / \mathrm{EVOH})}$,

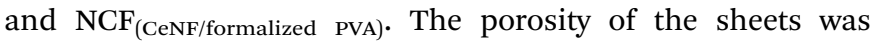
approximately $25 \%$ as shown in Table 2 . The interesting data in Table 2 are the water contact angles. The contact angle of $\mathrm{NCF}_{\text {(CeNF/PVA) }}$ sheet was $10^{\circ}$, and this result shows that the surface of the $\mathrm{NCF}_{(\mathrm{CeNF} / \mathrm{PVA})}$ sheet was very hydrophilic. In contrast, the contact angles of the $\mathrm{NCF}_{(\mathrm{CeNF} / \mathrm{EVOH})}$ sheet and $\mathrm{NCF}_{(\mathrm{CeNF} / \text { formalized PVA) }}$ sheet were $24^{\circ}$ and $34^{\circ}$, respectively. These results indicate that the hydrophobicity of the NCF surface could be controlled depending on the choice of coating crystal.

\section{Conclusions}

$\mathrm{NCF}_{\text {(CeNF/PVA) }}$ was prepared via crystallization of PVA from a dilute solution in the presence of CeNF. CeNFs acted as a nucleating agent for the PVA crystallization, and PVA spherulites grew on the CeNFs' surface. The dried $\mathrm{NCF}_{(\mathrm{CeNF} / \mathrm{PVA})}$ was well dispersed in water by sonication, and the mechanical properties of their composite films were improved even at low $\mathrm{NCF}_{(\mathrm{CeNF} / \mathrm{PVA}=1 / 5)}$ concentrations. CeNFs coated with EVOH crystals and formalized PVA crystals were prepared, and the resultant $\mathrm{NCF}_{(\mathrm{CeNF} / \mathrm{EVOH})}$ and $\mathrm{NCF}_{(\mathrm{CeNF} / \text { formalized }}$ PVA $)$ were hydrophobic in comparison to the $\mathrm{NCF}_{(\mathrm{CeNF} / \mathrm{PVA})}$. Therefore, the surface hydrophilicity of the NCF surface could be controlled by the choice of coating crystal.

\section{Acknowledgements}

This study was supported by the OKAYAMA Green Bio Project.

\section{References}

1 N. Nakagaito and H. Yano, Appl. Phys. A: Mater. Sci. Process., 2005, 80, 155-159.

2 Y. Nishiyama, J. Wood Sci., 2009, 55, 241-249.

3 B. Wang and M. Sain, Compos. Sci. Technol., 2007, 67, 25212527.

4 I. Diddens, B. Murphy, M. Krisch and M. Müller, Macromolecules, 2008, 41, 9755-9759.

5 T. Nishino, K. Takano and K. Nakamae, J. Polym. Sci., Part B: Polym. Phys., 1995, 33, 1647-1651.

6 W. Helbert, J. Y. Cavaille and A. Dufresne, Polym. Compos., 1996, 17(4), 604-611.

7 T. Nishino, I. Matsuda and K. Hirao, Macromolecules, 2004, 37, 7683-7687.

8 A. Alemdar and M. Sain, Compos. Sci. Technol., 2008, 68, 557565.

9 A. Isogai and Y. Kato, Cellulose, 1998, 5, 153-164.

10 D. Y. Kim, Y. Nishiyama and S. Kuga, Cellulose, 2002, 9, 361367.

11 F. Zhang, W. Qiu, L. Yang, T. Endo and T. Hirotsu, J. Mater. Chem., 2002, 12, 24-26.

12 H. Lönnberg, L. Fogelströn, M. A. S. A. S. L. Berglund, E. Malmström and A. Hult, Eur. Polym. J., 2008, 44, 29912997.

13 Y. Habibi, A. L. Goffin, N. Schiltz, W. Duquesne, P. Dubois and A. Dufrense, J. Mater. Chem., 2008, 18, 5002-5010.

14 L. Jue, A. Per and T. D. Lawrence, Polymers, 2008, 49, 12851296.

15 F. Nakatsubo, H. Yano and K. M. Hamada, JP Pat., 133436, 2013.

16 A. Olszewska, P. Eronen, L. S. Johansson, J. M. Malho, M. Ankerfors, T. Lindström, J. Ruokolainen, J. Laine and M. Österberg, Cellulose, 2011, 18, 1213-1226.

17 H. Nakatani, K. Iwakura, M. Hamadate, N. Okazaki, M. Aoyama and M. Terano, J. Appl. Polym. Sci., 2011, 122, 2798-2806.

18 S. Konagaya, T. Oshio and M. Hayashida, JP Pat., 051991, 2012.

19 S. Iwamoto, S. Yamamoto, S. H. Lee and T. Endo, Composites, Part A, 2014, 59, 26-29.

20 A. Omrani, L. C. Simon and A. A. Rostami, Mater. Sci. Eng., A, 2008, 490, 131-137.

21 K. Monobe and Y. Fujiwara, Kobunshi Kagaku, 1964, 21, 179185.

22 N. Fujimoto, T. Osugi and I. Sakurada, Kobunshi Kagaku, 1950, 2, 14-18.

23 T. Uchida, A. Mishima, T. Ikeda, M. Furukawa and K. Asanuma, J. Fiber Sci. Technol., 2017, 73, 1-7.

24 K. Tsuboi and T. Mochizuki, J. Polym. Sci., Part C: Polym. Symp., 1963, 1, 531-534.

25 E. H. Qua, P. R. Hornsby, H. S. S. Sharma, G. Lyons and R. D. McCall, J. Appl. Polym. Sci., 2009, 113, 2238-2247. 